\section{Polyuria and weight-loss associated with cimetidine}

\section{Sir,}

Acute interstitial nephritis (AIN) is a recognized side effect of numerous drugs, including cimetidine, and is frequently non-oliguric. ${ }^{1}$ There is only one previously published report ${ }^{2}$ of cimetidine-associated AIN featuring polyuria and weight-loss.

An otherwise healthy 52 year old male was found to have a duodenal ulcer. After 10 weeks of treatment with cimetidine, at standard dosage, he was admitted with a 3 week history of weight loss of $5 \mathrm{~kg}$, polyuria and polydipsia. Other symptoms included profuse nocturnal sweating, anorexia, headache and profound malaise. Abnormal findings on examination were a pyrexia of $38^{\circ} \mathrm{C}$, pallor and tenderness on deep palpation of the flanks. There was no rash, lymphadenopathy or evidence of arthritis, and he was normotensive.

On investigation, he was found to be anaemic (haemoglobin $11.8 \mathrm{~g} / \mathrm{dl})$, with an eosinophilia $\left(648 \times 10^{6} / \mathrm{l}\right)$ and a raised ESR ( $80 \mathrm{~mm} / \mathrm{first}$ hour). Urea was $11.8 \mathrm{mmol} / \mathrm{l}$, creatinine $0.290 \mathrm{mmol} / \mathrm{l}$, sodium $141 \mathrm{mmol} / 1$ and potassium $3.7 \mathrm{mmol} / \mathrm{l}$. He was hypocalcaemic $(2.09 \mathrm{mmol} / \mathrm{l})$, with normal levels of albumin, phosphate and glucose. Daily urine outputs were between 4 and 6 litres, creatinine clearance was $54 \mathrm{ml} / \mathrm{min}$ and 24 hour urinary protein $400 \mathrm{mg}$. Radiology of the renal tract and repeated urine microscopy and culture were normal. During a waterdeprivation test, the plasma osmolality rose from 285 to $305 \mathrm{mosmol} / \mathrm{kg}$, whilst the urine output remained relatively high $(\geqslant 70 \mathrm{ml} /$ hour $)$ and hypo-osmolar $(\leqslant 290$ $\mathrm{mosmol} / \mathrm{kg}$ ).

A diagnosis of impaired urine concentrating ability, probably due to AIN, was made, and the cimetidine was stopped. Within 3 days, the fever and other symptoms, apart from polyuria, had disappeared. Over the next 3 months, complete recovery ensued.

On the basis of at least 17 published reports, the manufacturers of cimetidine acknowledge AIN as a 'very rare complication, reversible on withdrawal of the drug'. In this case, a clinical diagnosis of drug-induced AIN was made on the basis of an episode of acute renal failure, associated with fever, eosinophilia, renal tenderness and evidence of tubulo-interstitial dysfunction, with rapid recovery upon withdrawal of the drug.

By interfering with the production of the medullary osmotic gradient, AIN is likely to result in a degree of impairment of urinary-concentrating ability. Reports of drug-associated AIN, featuring clinically manifest impaired urinary concentrating ability are, however, very rare. ${ }^{3-5}$ Cimetidine-induced AIN has only once previously been reported in association with polyuria. ${ }^{2}$

In conclusion, weight loss, subsequent upon polyuria, may be a presenting symptom of drug-induced AIN. This may be acute, as in my patient, or more chronic, with symptomatic polyuria only being manifest after some months of weight loss. ${ }^{2,4}$ Such weight loss could be mistakenly ascribed to the illness for which the offending drug is prescribed.

P.J. Mullen Medical Division, Royal Air Force Hospital, Halton, Aylesbury, Bucks HP22 5PG, UK.

\section{References}

1. Linton, A.L., Clark, W.F., Driedger, A.A., Turnbull, I. \& Lindsay, R.M. Acute interstitial nephritis due to drugs. Ann Intern Med 1980, 93: 735-741.

2. Detterbeck, F., Langenbach, R., Smith, J. \& Roxe, D.M. Recurrent fever of unknown origin with cimetidine-induced interstitial nephritis. J Infect Dis 1983, 148: 1131-1132.

3. Baldwin, D.S., Levine, B.B., McCluskey, R.T. \& Gallo, G.R. Renal failure and interstitial nephritis due to penicillin and methicillin. N Engl J Med 1968, 279: 1245-1252.

4. Masson, E.A. \& Rhodes, J.M. Mesalazine-associated nephrogenic diabetes insipidus presenting as weight-loss. Gut 1992, 33: $563-564$.

5. Quinn, B.P. \& Wall, B.M. Nephrogenic diabetes insipidus and tubulo-interstitial nephritis during continuous therapy with rifampicin. Am J Kid Dis 1989, 14: 217-220.

\section{Amiodarone and hair loss}

\section{Sir,}

We would like to report a case of hair loss and photosensitive rash associated with the use of amiodarone. A 61 year old woman with hypertrophic cardiomyopathy was started on amiodarone for paroxysmal ventricular tachycardia. She tolerated this well and had no problems until the development of a photosensitive skin rash 7 months later, during the summer, followed by marked hair loss from her scalp. Daily medication at this time was diltiazem $60 \mathrm{mg}$, bendrofluazide $5 \mathrm{mg}$, aspirin $150 \mathrm{mg}$, diazepam $2 \mathrm{mg}$, and amiodarone $200 \mathrm{mg}$. Therapy with amiodarone was stopped and the rash disappeared within 2 months. Hair loss only ceased about 3 months after discontinuation of amiodarone treatment, and there has been subsequent regrowth of scalp hair.

Amiodarone is well known for the variety of side effects associated with its use, ${ }^{1}$ but hair loss has only been reported previously in three patients. ${ }^{2,3}$ In our patient the temporal relationship between amiodarone treatment and the development and subsidence of both skin rash and hair loss suggest amiodarone as the causal agent. There were no other changes in medication over this period and no clinical evidence of thyroid dysfunction. Hair loss, though not life threatening, provokes great anxiety and social embarrassment in patients, and therefore deserves attention.

\section{L.M. Samuel M. Davie I.R. Starkey Departments of Cardiology and Pharmacy, Western General Hospital, Crewe Road, Edinburgh EH4 $2 X J, U K$.}

\section{References}

1. Walker, G. (ed.) ABPI Data Sheet Compendium 1991-92. Datapharm Publications Ltd, London, 1991, pp. 1347-1350.

2. Samanta, A., Jones, G. \& Burden, A. Adverse reactions during treatment with amiodarone hydrochloride. $\mathrm{Br} \mathrm{Med} J$ 1983, 287, 503.

3. McGovern, B., Garan, H., Kelly, E. \& Ruskin, J. Adverse reactions during treatment with amiodarone $\mathrm{HCl} . \mathrm{Br} \mathrm{Med} \mathrm{J}$ 1983, 287, 175-179. 